\title{
Tobacco Rob Extract as Green Corrosion Inhibitor for N80 Steel in HCl Solution
}

Yong Guo ${ }^{1,2}$, Meidan Gao ${ }^{1}$, Hefang Wang ${ }^{1, *}$, Zhiyong Liu ${ }^{1, *}$

${ }^{1}$ School of Chemical Engineering and Technology, Hebei University of Technology, Tianjin 300130, China

${ }^{2}$ NOOC Tianjin Chemical Research Design Institute, Tianjin 300131, China

${ }^{3}$ School of Marine Science and Engineering, Hebei University of Technology, Tianjin 300130, China

*E-mail: whf0618@163.com, liuzhiyong@hebut.edu.cn

doi: $10.20964 / 2017.02 .25$

Received: 23 October 2016 / Accepted: 6 December 2016 / Published: 30 December 2016

The inhibitive action of tobacco rob water extract (TRE) on corrosion of N80 steel in $\mathrm{HCl}$ solution was investigated by weight loss, electrochemical measurement, and surface analysis. Results show the main constituents responsible for corrosion inhibition properties of TRE were found to be the nicotine and other components which contain $\mathrm{C}$, O. And a maximum inhibition efficiency of $91.5 \%$ is achieved with $750 \mathrm{mg} \cdot \mathrm{L}^{-1}$ of TRE in $1 \mathrm{M} \mathrm{HCl}$ at $60{ }^{\circ} \mathrm{C}$. Polarization curves reveal that the TRE acts as a mixedtype inhibitor. The values of effective capacitance obtained by electrochemical impedance spectroscopy (EIS) are in the range of double layer capacitance. The adsorption behavior of TRE follows Langmuir adsorption isotherm and the activation parameters governing adsorption process were calculated and discussed.

Keywords: tobacco rob extract, corrosion inhibitor, polarization, EIS

\section{FULL TEXT}

(C) 2017 The Authors. Published by ESG (www.electrochemsci.org). This article is an open access article distributed under the terms and conditions of the Creative Commons Attribution license (http://creativecommons.org/licenses/by/4.0/). 